\title{
Pojav borove hržice (Thecodiplosis brachyntera) na Pokljuki v 2018
}

\section{Nikica OGRIS1* $^{1 *}$ Maarten DE GROOT ${ }^{1}$}

V oktobru 2018 smo na Pokljuki, ob planinski poti od Planine Konjščice do Tosca, opazili poškodbe rušja (Pinus mugo Turra) zaradi borove hržice ali borove muhe šiškarice, Thecodiplosis brachyntera (Schwagrichen 1835) (Diptera: Cecidomyiidae), sinonim Cecidomyia brachyntera Schwagrichen, 1835, angl. needle shortening gall midge, kar je nova najdba tega škodljivca v Sloveniji. Pred kratkim smo o borovi hržici poročali v letu 2016, ko smo jo potrdili na Dleskovški planoti (Ogris in De Groot, 2016).

Intenziteta poškodb je bila majhna, poškodovanih je bilo do $5 \%$ iglic posameznega grma rušja. Borova hržica je napadla iglice vrhnjih poganjkov (slika 2). Napadene iglice so porumenele in so že odpadale. Vsak par porumenelih iglic je vseboval majhno kamrico, kjer se je navadno razvijala ena ličinka oranžne barve (slika 3). Ličinka je bila na videz brez glave, brez oči in brez nog, velikosti $2,5 \times 1,0 \mathrm{~mm}$ (sliki 4 in 5). Borovi poganjki so imeli letošnje iglice krajše in le-te so bile odebeljene pri osnovi, kar predstavlja šiško (slika 6).

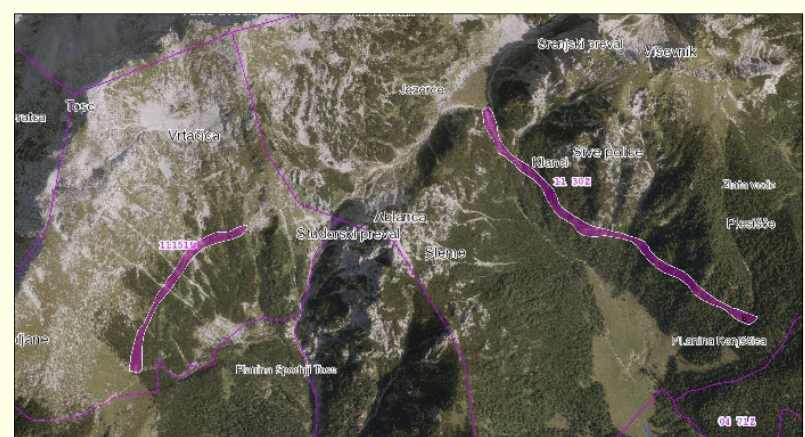

Slika 1: Karta zabeleženega napada borove hržice ob planinski poti od Planine Konjščice do Tosca (pripravil N. Ogris)
Borova hržica je domnevno v Sloveniji zelo pogosta in lahko povzroča precejšnje škode. Vendar manjkajo podatki o njeni dejanski razširjenosti, pogostosti in dejanskemu vplivu na zdravstveno stanje borov. Zelo verjetno se bodo poškodbe borov zaradi borove hržice v prihodnosti povečale zaradi toplejšega podnebja. Zato bi morali posvetiti več pozornosti njenim raziskavam.

\section{Viri}

Ogris N., De Groot M. 2016. Pojav borove hržice (Thecodiplosis brachyntera) na Dleskovški planoti v 2016. Novice iz varstva gozdov, 9: 27-28. DOI: 10.20315/NVG.9.8. Povezava: https://www.zdravgozd.si/nvg/prispevek.aspx?idzapis=9-8

Gozdarski inštitut Slovenije, Večna pot 2, 1000 Ljubljana *nikica.ogris@gozdis.si

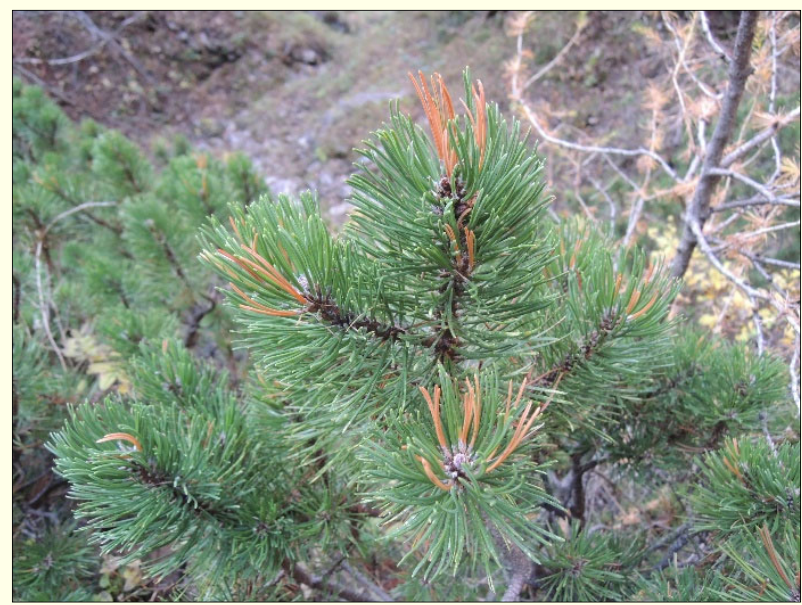

Slika 2: Grm rušja je poškodovala borova hržica (Thecodiplosis brachyntera) (Foto: N. Ogris) 


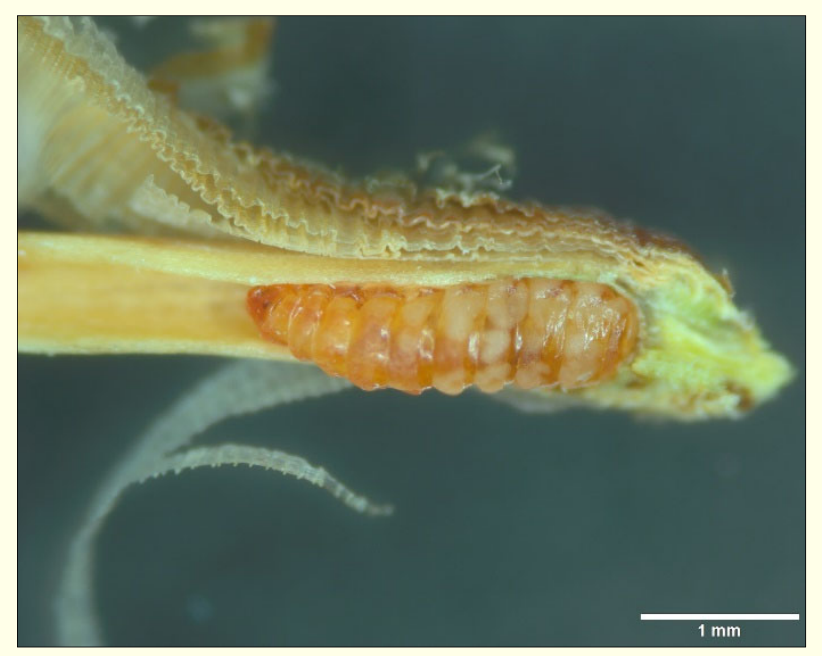

Slika 3: Ličinka borove hržice (Thecodiplosis brachyntera) se prehranjuje v osnovi iglice (Foto: N. Ogris)

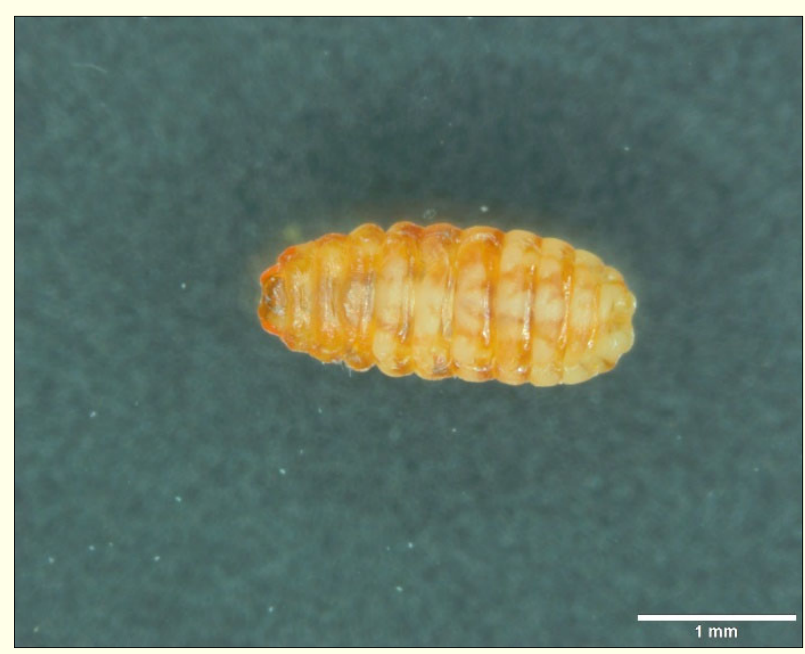

Slika 5: Ličinka borove hržice (Thecodiplosis brachyntera) - od zgoraj (Foto: N. Ogris)

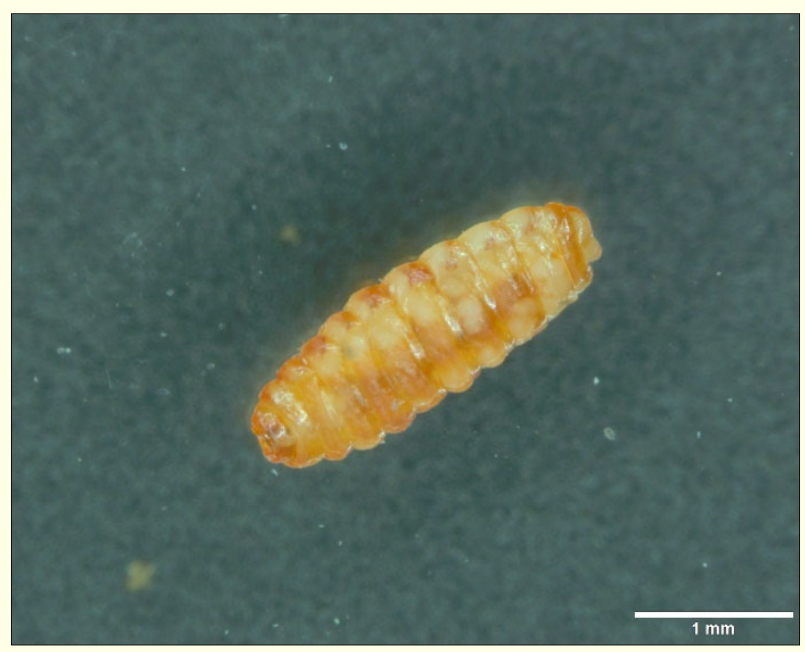

Slika 4: Ličinka borove hržice (Thecodiplosis brachyntera) - od spodaj (Foto: N. Ogris)

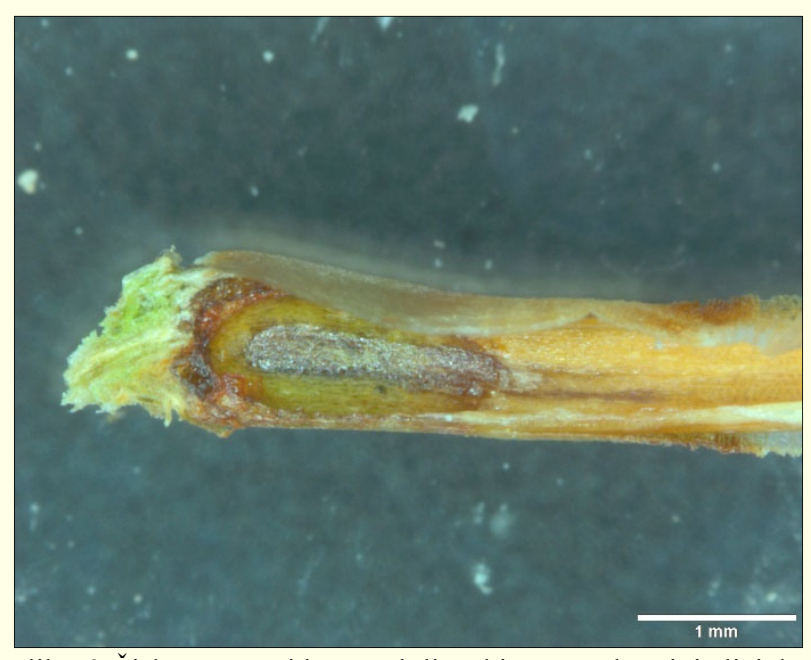

Slika 6: Šiška v osnovi borove iglice, kjer se prehranjuje ličinka borove hržice (Thecodiplosis brachyntera) (Foto: N. Ogris) 